\title{
Important Issues to Quality of Life Among Norwegian Older Adults: An Exploratory Study
}

\author{
Mary Kalfoss* and Liv Halvorsrud
}

\author{
Diakonova University College, Linstowsgate 5, 0166, Oslo, Norway
}

\begin{abstract}
The increasing numbers of older people and higher expectations of a "good life" within societies, has lead to international interest in the enhancement of quality of life (QoL) among older adults. Understanding whether the same aspects of life are equally important to the life quality of subgroups of older people is important in helping health professionals plan social and health care policy and caring strategies. The purpose of this study was to describe the importance given to 38 areas of QoL among Norwegian older adults and to identify differences in importance ratings by age, gender, marital and health status. This exploratory study was conducted with 379 older adults (mean age 73.3 years, SD 6.9) consisting of two cohorts. The first cohort $(n=287)$ comprised of non-hospitalized participants, were recruited from two national senior organizations, two political senior organizations and a voluntary organization in Eastern Norway. Participants responded to a postal survey. The second cohort $(n=92)$ comprised of hospitalized and ambulatory patients, were recruited from three medical wards and one outpatient clinic at a county hospital in Eastern Norway. Data was collected by personal interviews and interview assisted. All importance ratings were found to reflect substantial areas of importance. Highest mean importance was assigned to activities of daily living, mobility, sensory abilities, health and home environment. Least important was sex life, adequate social help, chance to learn new skills, body image and appearance and free of dependence on medications and treatment. There were a number of significant mean group differences by age, gender, marital and health status. Sixteen of the items detected significant between- group differences. Future application of the importance questions could facilitate understanding and recognition of important issues in subgroups of older adults.
\end{abstract}

Keywords: Ageing, importance ratings, nursing, scale development, quality of life.

\section{INTRODUCTION}

The increasing numbers of older people, and higher expectations of a "good life" within societies, has lead to international interest in the enhancement and measurement of quality of life (QoL) in older age [1]. Although most people would agree that everyone has a QoL and possesses an intuitive understanding of what the concept means $[2,3]$, QoL is a subjective experience representing varying things to different people. The main domains of QoL can differ in value and priority among different age groups in varied phases of their lives. Thus, what was once important may seem unimportant, while things once ignored may have great relevancy [4]. Studies have also shown the subjective importance given to aspects of QoL are influenced by individual's health, expectations, aspirations, personal beliefs, cultural belief systems, and socio-demographic factors such as age, sex, socio-economic status, education and marital status [5, $6]$.

\section{RELATED LITERATURE}

Evans and colleagues [7], in exploring the importance of QoL domains in older people, conducted 100 interviews with older adults of all ages and with varying levels of ability and found that family, finances, social life, leisure, health and

*Address correspondence to this author at the Diakonova University College, Linstowsgate 5, 0166, Oslo, Norway; Tel: 47229853 50; Fax: 47.229863 50; E-mail: Mary.kalfoss@c2i.net living arrangements were considered important to over $80 \%$ of the adults studied. Beaumont and colleagues [8] collected data in interviews with 190 older adults (aged 65 years or more) living in London using the Schedule for Evaluation of Individual Quality of Life - Direct Weighting (SEIQol-DW). The highest average que rates indicating "importance" were partner, family, health, church attendance, mobility, lunch club, participation, independence, freedom of choice, home, emotional well being, independence, caring for self, transport, companionship, financial security and personal security related to family, health, and home. In a recent review of the literature, Brown et al. [1] found that healthy older people consistently reported relationships with family and others, independence and autonomy, finances, health, spirituality and institutional care as important to their QoL. Saxena et al. [9] reported on importance ratings of facets included in the World Health Organization Quality of Life-BREF (WHOQOL-BREF) in a sample of 4804 healthy and ill people (mean age 45.6 years) from 15 countries. The highest mean ratings were daily living activities (ADL), energy, overall health, happiness and enjoyment in life. The lowest ratings included environment, support from others, body image and appearance and sex life.

Noteably, in a recent review of QoL studies among older adults, the authors reported the effect of heterogeneity in respondent characteristics was largely ignored [1] although various studies have shown sub group differences. Regarding differences in age groups, results of various national British health surveys, have reported that social relationships and work 
are prioritized more by younger adults and health more by people aged 65 and over [10-12]. Farquhar [13] found that family and activities were mentioned most often among older adults living at home in two contrasting areas of south east England, while health was prioritized among the older - old. Similarly, in a randomized postal survey of 2000 British adults, Bowling [12] found that older old (over 75) prioritized health and mobility as compared to the younger old who prioritized relationships with family and other relatives, finances and work.

Regarding the relationship of health status and QoL, Puts and colleagues conducted qualitative interviews with 25 adults [14] and found that health was given highest priority, whereas, among frail adults, social contacts was found most important. Arnold [15] found among institutionalized elderly, that physical functioning and symptoms, emotional- behavioural- cognitiveintellectual- social functioning and the existence of social support, life satisfaction, health perception, economic status, ability to pursue interests and recreation, sexual function, energy and vitality were especially important to the frail elderly.

In examining the relationship of QoL and gender, sociodemographic and clinical variables among 13, 000 communitybased older adults, Lubetkin [16] in a USA health population survey, found lower QoL was related to being female, having lower income, lower education and reduced health status. Bowling and Gabriel [17] compared theoretically derived QoL indicators from a national British survey of older people with their own definitions of QoL and found that social comparisons and expectations, personality and psychological characteristics (optimism - pessimism), health and functional status, personal social capital (social contacts, support, loneliness), neighbourhood, social capital, (perceived quality of neighbourhood facilities and safety) explained the largest variance in QoL ratings. However, these authors found that socio - economic factors contributed very little to the model. In investigating gender differences among older adults in a five year follow-up study after total hip replacement $(n=627), \mathrm{Ng}$ et al. [18] reported lower QoL scores pre-operatively for females, although gender differences did not continue post operatively. al-Windi and colleagues who conducted a Swedish postal survey among older adults [19] found that men had significantly higher score on physical wellbeing than women and those married had significantly higher scores on QoL as compared to those who were single. Lastly in another Swedish survey, Hellström and Hallberg [20] reported that high QoL among older adults, age 77-89 living at home with help from informal and formal caregivers, was significantly related to living with someone, higher age and lower number of health complaints and managing to be alone.

In summary, although there are a number of international studies reporting varied issues of importance to older adults, to our knowledge there have been no previous studies describing important aspects to QoL among subgroups of older Norwegian adults. Norway, like many other Western countries, is faced with challenges due to an ageing society. For example, Norway has a growing number of people leaving work through early retirement schemes from the age of 62 . Norway also has an extensive social and health welfare system based upon socialistic values. One contributing factor to this system is the wealth the country has accumulated from their extraction of petroleum in the North Sea. Whether economic growth and the value given to social and health welfare provision is being accompanied by increasing or declining personal satisfaction with QoL in subgroups of older adults should be of vital interest. Economical growth doesn't always succeed in generating a greater sense of well being or secure the provision of adequate social and health services. Moreover, economical growth at the societal level may aggregate consequences that undermine QoL at the individual level. It is important therefore, to understand the important determinants of QoL in various subgroups of older adults in order to support evidence-based policy guidelines, program development and policy decisions. Hence, the aim of this article is to describe the importance given to 38 areas of QoL to older adults and identify differences in importance ratings by age, gender marital and health status.

Using importance ratings included in the World Health Organization Quality of Life - 100 (WHOQOL-100) and World Health Organization Quality of Life - BREF (WHOQOLBREF), the objectives of the study were to explore: (1) the relative importance of various aspects of life in contributing to its quality among Norwegian older adults aged 60 years or older; (2) the relative importance of various aspects of life contributing to QoL among older adults by age, gender, marital status and health status; and (3) the internal consistency and discriminatory power of the importance ratings.

\section{MATERIAL AND METHODOLOGY}

Data was collected as part of a larger international study which had as its aim the developing and testing of the World Health Organization Quality of Life - Old (WHOQOL-OLD) -a new add-on module for use with the WHOQOL-100-- to specifically assess the QoL of adults over 60 years [21]. The pilot testing was carried out in 22 WHOQOL centers including Norway. Data was collected for the pilot study in Norway during 2002 - 2003. All variables had fewer than 3\% missing values except for items relating to sex life $(9.2 \%)$ and free of dependence on medication and treatment $(6.1 \%)$.

\section{Participants}

The international protocol stipulated that each centre obtain a minimum of 300 older adults, with equal numbers of men and women (50\%), people aged 60 to 80 years, and over 80 years, with both healthy and ill respondents. The Norwegian convenience sample $(n=379)$ comprised two cohorts. The first cohort $(n=766)$ which we defined as our healthy group were non-hospitalized. Participants were recruited by contacting 25 institutions and organizations in Norway. These organizations included two national senior organizations, 15 district and regional senior and political organizations and 3 voluntary organizations. First, all organizations were contracted per telephone by the second author. Five institutions/organizations agreed to take part in the study. These organizations included the two national senior organizations, a voluntary organization for seniors and two senior political organizations. Reasons given for not wanting to take part in the study were anticipated difficulties in recruiting participants, incomplete addresses and shortage of time. Organizations agreeing to take part in the study received a formal written invitation. Contact persons at these institutions recruited potential participants according to the following inclusions criteria: participants over 60 years who were not presently hospitalized or had known reduced cognitive function. Contact persons held administrative positions in the national organizations and had an overview 
of national members. Contact persons at the senior organizations were healthcare workers affiliated with these organizations working in administrative positions. Information regarding the study was presented by them personally at organizational meetings. Those who agreed to participate were posted self-complete questionnaires by the second author. Questionnaires were sent to 766 persons with 287 responding, giving a response rate of $43 \%$. All participants signed a written informed consent.

The second cohort, representing the unhealthy respondents, included 92 older adults recruited from three medical wards from a 670-bed hospital and ambulatory clinic in Eastern Norway. The medical wards were composed largely of patients with heart, lung and cancer problems. Nursing administration appointed contact nurses who recruited potential participants. Inclusions criteria included: over 65 years (age range required by hospital due to ongoing research projects), presently hospitalized/attending ambulatory clinic and had given informed consent. Exclusions criteria included; terminal illness, acute critical illness situation, reduced cognitive status, no present or previous psychiatric treatment the past 5 years, and reduced reading, writing and hearing problems. Contact nurses screened participants for cognitive functioning using clinical judgement and provided oral and written information. Data was collected by personal interviews and interview-assisted. The second author and two other health professionals experienced in interviewing carried out the personal interviews. Ninety-five patients agreed to take part in the study, with three withdrawing due to illness complications, leaving a sample of 92. All participants signed a written informed consent. Two cohorts were chosen for the study because the authors were interested in comparing methodological approaches although this is not the focus of the present paper.

\section{Measures}

The study measures included the WHOQOL-100, WHOQOL-OLD, importance questions for all WHOQOL dimensions assessed and a set of socio-demographic and health-related questions.

The WHOQOL-100 [22] is an established measure of QoL. The WHOQOL-100 core items were developed following a program of qualitative and quantitative work agreed upon by international research collaboration [22, 23]. The 100 items are organized into 24 facets of QoL, grouped into six domains. Four questions assess overall QoL and satisfaction with health. The instrument shows good internal consistency reliability with Cronbach's alphas above .7 for almost all facets (.65-.93) Test-retest reliability over 2-8 weeks ranged from .68 to .95 The instrument has been found to discriminate between people who are sick and well, and the construct validity and factor structure has been validated using both exploratory and confirmatory factor analyses [22]. Cronbach's alpha for Norwegian version of the WHOQOL-100 is $\alpha=.86$. Although the qualitative and quantitative work had ensured that all facets included in the WHOQOL-100 were considered important in all centers, a set of items were included in the questionnaire specifically asking about the importance of the facets to QoL. These importance items are described below.
The WHQOL-OLD is a new instrument that is designed to be an add-on module for the WHOQOL measures for older adults [21]. A 40 - item pilot version of the WHOQOLOLD module was administered. The model was derived following standard methodology. In the pilot phase of the study, 22 centers from around the world carried out focus groups with older adults, with carers, and with health professionals working with older adults in order to identify gaps in the coverage of the WHOQOL-100 that were relevant specifically for older adults. Additionally, the focus work suggested six supplementary facets for existing WHOQOL facets. These facets include sensory abilities, intimacy, past, present and future activities, death and dying, social participation, and autonomy [21]. Items generated from the focus groups were then tested in over 7400 respondents with analyses using both classical and modern psychometric methods. These analyses indicated a further gap in the coverage of the items, so further items were generated that specifically assessed intimate relations. A field trial study was later carried out with approximately 5500 respondents, again with the use of both classical and modern psychometric methods. The outcome of this second round of data collection and analyses is a 24-item, 6 facet model which can be used with in conjunction with the WHOQOL-BREF or the WHOQOL-100 for assessment of QoL in older adults. The Norwegian version showed good internal consistency reliability with $\alpha=.89$.

Because different cultures would be likely to ascribe a distinctive profile of importance values to QoL dimensions, the WHOQOL importance items were originally developed to test this. They were originally intended to weight scores with the aim of improving cross - national equivalence between language versions [24]. The importance questions are related to 38 facets of QoL included in the WHOQOL100 and the WHOQOL-OLD. In addition, two overall items assessing overall quality of life and health were also retained. Respondents are asked to report on how important each aspect of life is to them and how much it affects their QoL. No specific time period is suggested. Items are measured on a 5-point Likert scale from not important (1) to extremely important (5). The Norwegian version shows good internal consistency reliability with $\alpha=.92$.

\section{Data Analysis}

Data were analyzed with SPSS [25]. Frequency distributions and descriptive statistics were calculated. Pearson correlation coefficients were used to explore itemto-item importance ratings and item-to-facet correlations with the WHOQOL-100. Group differences were analyzed with unpaired Student $t$ tests (the groups were: male/female, younger-aged 60 - 74 years /older- aged 75 - 90 years, cohabitating (married, formally and informally partnered)/not cohabitating (unmarried, separated, divorced, living alone) and healthy (not hospitalized) and ill (hospitalized or attending the outpatient ambulatory clinic). To analyze internal consistency of the instruments, Cronbach's alpha was applied. A Cronbach's alpha coefficient above .70 indicates good reliability [26-29]. According to WHOQOL guidelines [30] use of data is not recommended for research purposes when more than $20 \%$ of the items are missing There were $20.3 \%$ cases with missing data $(n=77)$ and these respondents were omitted from the statistical analyses, leaving a total sample of 379. A $p$ - value 
of 0.01 was regarded as statistically significant. To illustrate what differences can be expected to be found in these comparisons, we have performed a power calculation based on the size of the subgroups and assumed a common standard deviation within the groups. Based on our data we have used a common standard deviation of 0.7 . We then have $80 \%$ power to be able to detect differences ranging from 0.21 (comparing age groups) up to 0.24 (comparing gender). Looking at the differences we have uncovered, they are all approximately of this magnitude.

\section{Ethical Considerations}

The study was reviewed and approved by the Regional Ethics Committee ( $\$$ 21902087) and the Norwegian Social Science Data Services. All respondents gave written informed consent to enrollment in the study and were informed that participation was voluntary and confidentiality was guaranteed.

\section{RESULTS}

Descriptive characteristics are presented in Table 1. The mean age of the sample was 73.3 (range: $60-90$ years). The majority of adults were female (74.1\%). Almost half of the sample was cohabitating (47.2\%), with $87.9 \%$ living in their own homes and $6.9 \%$ in institutions. Nearly two-thirds of the sample (68.6\%) had completed vocational school, college or university.

\section{Important Ratings and Sub Group Differences}

Mean importance ratings (mean, SD, median and inter quartile ranges) for the total sample is presented in Table $\mathbf{2}$. All mean importance ratings were greater then 3.0 on a 5 point scale demonstrating that these issues were appraised as moderately important to extremely important, except sex life. The highest mean importance ratings were ability to perform ADL $(M=4.67, S D=.55)$, ability to move around $(M=4.55, S D=.58)$, sensory abilities $(M=4.55, S D=.63)$, health $(M=4.46, S D=.59)$, and home environment $(M=$ $4.42, S D=.60)$. Lowest mean importance ratings were sex life $(M=2.21, S D=1.25)$, adequate social help $(M=3.10$, $S D=1.37)$, chances to learn new skills $(M=3.17, S D=$ $1.06)$, body image and appearance $(M=3.40, S D=.86)$ and free of dependence on medications and treatment $(M=3.62$, $S D=1.22$ ).

\section{Differences in Age Groups}

Statistically significant mean group differences in important ratings are presented in Table 3. Three significant differences in important issues were reported by the younger age group. Younger aged (60 - 74 years) assessed feeling positive about self $(\mathrm{t}=3.07(\mathrm{df}=268.48) p<.002)$, chances to learn new skills $(\mathrm{t}=3.74(\mathrm{df}=366) p<.001)$, and sex life $(\mathrm{t}=4.94(\mathrm{df}=342) p<.001)$ as being more important than the older age group ( 75 - 90 years).

\section{Differences in Gender and Marital Status}

Gender differences in importance ratings are also shown in Table 3. There were nine issues perceived more important to women as compared to men. These issues included: sensory abilities $(\mathrm{t}=3.99(\mathrm{df}=361) p<.001)$, relation with others $(\mathrm{t}=2.64(\mathrm{df}=358) p<.009)$, ability to learn and remember important information $(\mathrm{t}=3.5(\mathrm{df}=359) p<.001)$, feeling hopeful $(\mathrm{t}=2.92(\mathrm{df}=360) p<.004)$, positive attitudes towards death and dying $(\mathrm{t}=5.48(\mathrm{df}=110.86) p<.001)$, personal beliefs $(\mathrm{t}=8.04(\mathrm{df}=358)(\mathrm{p}<.001)$, able to participate in community $(\mathrm{t}=3.98(\mathrm{df}=121.87) p<.001)$, able to think through everyday problems and make decisions $(\mathrm{t}=3.30(\mathrm{df}=357)$ $p=.001$ ), and body image and appearance

Table 1. Sociodemographic Characteristics

\begin{tabular}{|c|c|c|}
\hline Sociodemographic Characteristics & $\mathbf{N}(\%)$ & Missing (\%) \\
\hline \multicolumn{3}{|l|}{ Age } \\
\hline Mean (years) & 73.3 (SD.6.9) & \\
\hline Range (years) & $60-90$ & \\
\hline $60-74$ years & $224(59.1)$ & \\
\hline 75 - years & $155(40.9)$ & \\
\hline$\underline{\text { Gender }}$ & & $13(3.4)$ \\
\hline Female & $281(74.1)$ & \\
\hline Male & $85(22.4)$ & \\
\hline Marital status & & $14(3.7)$ \\
\hline Married & $179(47.2)$ & \\
\hline Not married & $65(17.2)$ & \\
\hline Widow/ widower & $105(27.7)$ & \\
\hline Divorced & $11(2.9)$ & \\
\hline Partner & $5(1.3)$ & \\
\hline Education & & $13(3.4)$ \\
\hline Basic & $106(28)$ & \\
\hline Higher & $236(62.3)$ & \\
\hline University & $24(6.3)$ & \\
\hline Living area & & $17(4.5)$ \\
\hline Urban & $270(71.2)$ & \\
\hline Rural & $92(24.3)$ & \\
\hline Living arrangements & & $20(5.3)$ \\
\hline Living at home & $333(87.9)$ & \\
\hline Living in institution & $26(6.9)$ & \\
\hline$\underline{\text { Finances }}$ & & $13(3.4)$ \\
\hline Very good & $66(17.4)$ & \\
\hline Good & $218(57.5)$ & \\
\hline Average & $71(18.7)$ & \\
\hline Poor & $6(1.6)$ & \\
\hline Very poor & $5(1.3)$ & \\
\hline Health Status & & 0 \\
\hline Hospitalized & $92(24.3)$ & \\
\hline Not Hospitalized & $287(75.7)$ & \\
\hline
\end{tabular}

$(\mathrm{t}=2.85(\mathrm{df}=358) p<.005)$. Men, however, rated being free of pain $(\mathrm{t}=-2.82(\mathrm{df}=177.71) p<.008)$ and sex life $(\mathrm{t}=$ $-4.04(\mathrm{df}=336) p<.001)$ as being more important than women. 
Table 2. Rank Order of Mean Importance Ratings $(n=379)$

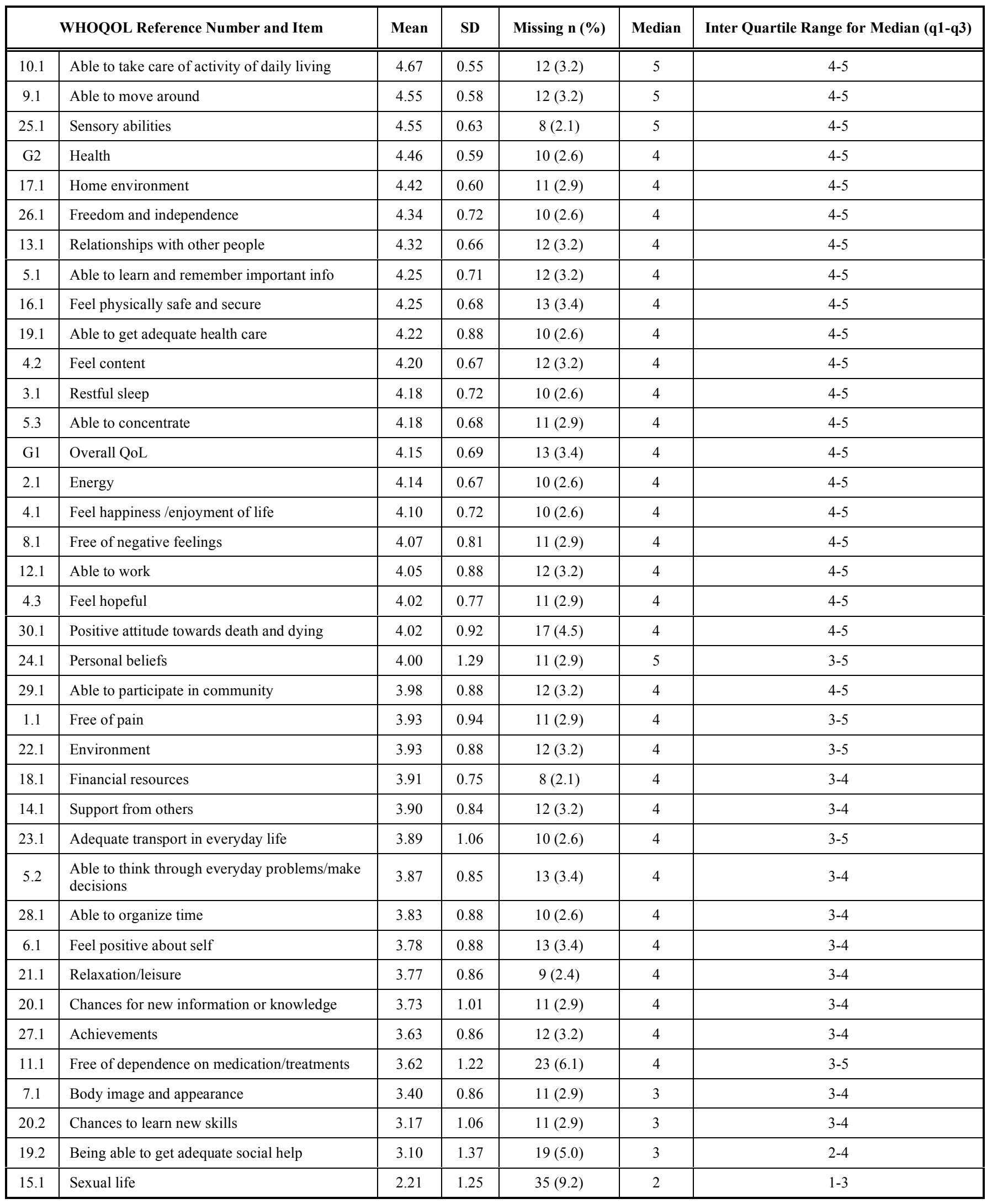


Table 3. Statistically Significant Mean Differences in Importance Ratings by Age-Groups, Gender, Marital and Hospital Status

\begin{tabular}{|c|c|c|c|c|c|c|c|c|c|}
\hline & & $\begin{array}{r}\text { Means/Di } \\
\text { by A }\end{array}$ & erence & $\begin{array}{r}\text { Means/D } \\
\text { by Ge }\end{array}$ & $\begin{array}{l}\text { ference } \\
\text { der }\end{array}$ & $\begin{array}{r}\text { Means/D } \\
\text { Mari }\end{array}$ & $\begin{array}{l}\text { erence by } \\
\text { Status }\end{array}$ & $\begin{array}{r}\text { Means/Differ } \\
\text { S }\end{array}$ & $\begin{array}{l}\text { ce by Hospital } \\
\text { us }\end{array}$ \\
\hline & Q & Rolow 75 & 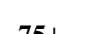 & Fomolo & Molo & With & Without & Non- & Hosnitolizad $>2$ \\
\hline 10.1 & $\begin{array}{l}\text { Able to take care of activity of daily } \\
\text { living }\end{array}$ & 4.72 & 4.59 & 4.69 & 4.64 & 4.71 & 4.62 & 4.68 & 4.62 \\
\hline 9.1 & Able to move around & 4.59 & 4.49 & 4.55 & 4.58 & 4.14 & 3.94 & 4.53 & 4.60 \\
\hline 25.1 & Sensory abilities & 4.57 & 4.51 & $4.63^{*}$ & $4.33^{*}$ & 4.53 & 4.56 & $4.59^{*}$ & $4.40^{*}$ \\
\hline G2 & Overall health & 4.48 & 4.42 & 4.45 & 4.50 & 4.48 & 4.43 & 4.45 & 4.48 \\
\hline 17.1 & Home environment & 4.47 & 4.35 & 4.43 & 4.44 & 4.55 & 4.28 & 3.91 & 3.99 \\
\hline 26.1 & Freedom and independence & 4.36 & 4.31 & 4.37 & 4.31 & 4.27 & 4.42 & 4.37 & 4.25 \\
\hline 13.1 & Relationships with other people & 4.33 & 4.29 & $4.38^{*}$ & $4.17^{*}$ & 4.31 & 4.31 & 4.34 & 4.25 \\
\hline 5.1 & $\begin{array}{l}\text { Able to learn and remember important } \\
\text { information }\end{array}$ & 4.27 & 4.21 & $4.32^{*}$ & $4.02^{*}$ & 3.74 & 3.74 & 4.25 & 4.24 \\
\hline 16.1 & Feel physically safe and secure & 4.25 & 4.24 & 4.30 & 4.10 & 4.26 & 4.23 & 4.26 & 4.21 \\
\hline 19.1 & Able to get adequate health care & 3.08 & 3.12 & 4.19 & 4.31 & 4.23 & 4.20 & $4.11^{*}$ & $4.59^{*}$ \\
\hline 4.2 & Feel content & 4.22 & 4.16 & 4.22 & 4.17 & 4.28 & 4.11 & 4.15 & 4.21 \\
\hline 3.1 & Restful sleep & 4.18 & 4.18 & 4.22 & 4.02 & 4.15 & 4.20 & 4.17 & 4.23 \\
\hline 5.3 & Able to concentrate & 4.25 & 4.09 & 4.24 & 4.11 & 4.21 & 4.16 & 4.17 & 4.23 \\
\hline G1 & Overall QoL & 4.15 & 4.14 & 4.20 & 4.04 & 4.16 & 4.16 & 4.16 & 4.09 \\
\hline 2.1 & Energy & 4.17 & 4.10 & 4.17 & 4.12 & 4.19 & 4.09 & 4.16 & 4.09 \\
\hline 4.1 & Feel happiness /enjoyment of life & 4.05 & 4.22 & 4.06 & 4.25 & $4.23^{*}$ & $3.96^{*}$ & $4.03^{*}$ & $4.34^{*}$ \\
\hline 8.1 & Free of negative feelings & 4.05 & 4.10 & 4.05 & 4.17 & 4.12 & 4.03 & $4.01^{*}$ & $4.29^{*}$ \\
\hline 12.1 & Able to work & 4.10 & 3.98 & 4.11 & 3.86 & 4.11 & 3.86 & $4.14^{*}$ & $3.74^{*}$ \\
\hline 4.3 & Feel hopeful & 4.04 & 4.00 & $4.10^{*}$ & $3.83^{*}$ & 4.08 & 3.98 & 4.02 & 4.02 \\
\hline 30.1 & $\begin{array}{l}\text { Positive attitude towards death and } \\
\text { dying }\end{array}$ & 4.07 & 3.96 & $4.20^{*}$ & $3.51^{*}$ & 3.97 & 4.10 & $4.11^{*}$ & $3.71^{*}$ \\
\hline 24.1 & Personal beliefs & 4.02 & 3.97 & $4.30^{*}$ & $3.12^{*}$ & 3.88 & 4.15 & $4.19^{*}$ & $3.38^{*}$ \\
\hline 29.1 & Able to participate in community & 4.03 & 3.89 & $4.09^{*}$ & $3.65^{*}$ & 3.89 & 4.05 & $4.06^{*}$ & $3.68^{*}$ \\
\hline 1.1 & Free of pain & 3.85 & 4.05 & $3.86^{*}$ & $4.14^{*}$ & 3.97 & 3.87 & $3.86^{*}$ & $4.16^{*}$ \\
\hline 22.1 & Environment & 3.97 & 3.87 & 3.95 & 3.74 & $4.55^{*}$ & $4.28^{*}$ & 4.40 & 4.51 \\
\hline 18.1 & Financial resources & 3.90 & 3.91 & 3.95 & 3.80 & 3.86 & 3.96 & 3.91 & 3.91 \\
\hline 14.1 & Support from others & 3.98 & 3.78 & 3.95 & 3.74 & 3.88 & 3.90 & 3.85 & 4.06 \\
\hline 23.1 & Adequate transport in everyday life & 3.86 & 3.92 & 3.87 & 3.96 & 3.79 & 3.99 & $3.81^{*}$ & $4.14^{*}$ \\
\hline 5.2 & $\begin{array}{l}\text { Able to think through everyday } \\
\text { problems/make decisions }\end{array}$ & 3.95 & 3.74 & $3.97^{*}$ & $3.64^{*}$ & 3.87 & 3.90 & 3.92 & 3.68 \\
\hline 28.1 & Able to organize time & 3.89 & 3.75 & 3.90 & 3.67 & 3.81 & 3.84 & 3.85 & 3.75 \\
\hline 6.1 & Feel positive about self & $3.90^{*}$ & $3.60^{*}$ & 3.83 & 3.70 & 3.81 & 3.84 & 3.77 & 3.82 \\
\hline 21.1 & Relaxation/leisure & 3.83 & 3.68 & 3.80 & 3.74 & 3.76 & 3.77 & 3.76 & 3.82 \\
\hline 20.1 & $\begin{array}{l}\text { Chances for new information or } \\
\text { knowledge }\end{array}$ & 3.78 & 3.67 & 3.82 & 3.58 & 3.74 & 3.74 & 3.77 & 3.60 \\
\hline 27.1 & Achievements & 3.67 & 3.57 & 3.68 & 3.55 & 3.62 & 3.65 & 3.64 & 3.59 \\
\hline 11.1 & $\begin{array}{l}\text { Free of dependence on medication/ } \\
\text { treatments }\end{array}$ & 3.61 & 3.61 & 3.67 & 3.56 & 3.70 & 3.56 & 3.65 & 3.53 \\
\hline 7.1 & Body image and appearance & 3.45 & 3.34 & $3.49^{*}$ & $3.19^{*}$ & 3.42 & 3.40 & 3.47 & 3.19 \\
\hline 20.2 & Chances to learn new skills & $3.33^{*}$ & $2.92^{*}$ & 3.27 & 2.96 & 3.22 & 3.12 & 3.23 & 2.96 \\
\hline 19.2 & Being able to get adequate social help & 3.08 & 3.12 & 3.06 & 3.18 & 2.96 & 3.20 & $2.97^{*}$ & $3.51^{*}$ \\
\hline 15.1 & Sexual life & $2.47^{*}$ & $1.81^{*}$ & $2.06^{*}$ & $2.69^{*}$ & $2.69^{*}$ & $1.66^{*}$ & 2.19 & 2.28 \\
\hline
\end{tabular}

Significant at $p<0.01$.

In exploring statistical significant differences in marital status, those with partners assessed three issues as more important than nonpartnered. These issues included: feeling happiness and enjoyment in life $(\mathrm{t}=3.77(\mathrm{df}=359) p<.001)$, environment $(\mathrm{t}=4.44(\mathrm{df}=358) p<.001)$ and sex life $(\mathrm{t}=8.23$ $(\mathrm{df}=335) p<.001)$. 


\section{Differences in Hospitalized and Non-hospitalized Groups}

There were five significant perceived differences in importance rated as more important by those who were not hospitalized. Sensory abilities $(\mathrm{t}=2.58(\mathrm{df}=369) p<.01)$, work $(\mathrm{t}=3.27(\mathrm{df}=113.85) p=.001)$, positive attitudes towards death and dying $(\mathrm{t}=3.16(\mathrm{df}=112.96) p<.002)$, personal beliefs $(\mathrm{t}=$ $5.86(\mathrm{df}=366) p<.001)$, and participation in the community $(\mathrm{t}=$ $3.09(\mathrm{df}=112.52) p<.002)$, were perceived as more important. Those hospitalized assigned more importance to six issues: adequate health care $(\mathrm{t}=-4.55(\mathrm{df}=367) p<.001)$, feeling happiness and enjoyment $(\mathrm{t}=-3.52(\mathrm{df}=367) p<.001)$, being free of negative feelings $(\mathrm{t}=-2.87(\mathrm{df}=366) p<.004)$, being free of pain $(\mathrm{t}=2.66(\mathrm{df}=366) p<.008)$, transport $(\mathrm{t}=-2.92(\mathrm{df}$ $=178.81) p<.004)$ and adequate social help $(\mathrm{t}=-3.21(\mathrm{df}=358)$ $p=.001)$.

Altogether, over one half of the importance items $(n=$ $20,52.6 \%$ ), detected significant group differences. Only one item (sex life) showed discriminate power across all groups when using a significance level of p- value 0.01 .

\section{Discriminatory Power and Internal Consistency of the Importance Items}

The item-to-item correlations of the importance ratings showed that the correlation coefficients were small and not consistently high. The smallest correlations were between personal beliefs and able to get adequate health care $(r=$ $.000, p<.991)$. Highest correlations were between feeling content and feeling happiness/enjoyment in life, $(r=.69, p<$ $.001)$. The greatest number of nonsignificant correlations were found for sex life and personal beliefs, with eight and seven non-significant associations, respectively. Correlations between individual importance ratings and WHOQOL-100 facets showed that the correlations were small to moderate. The smallest correlation was between the item able to learn and remember important information and the social support facet $(r=10, p<05)$. The highest correlation was between the item personal beliefs and the spirituality facet, $(r=.74, p$ $<.01)$. All items were significantly correlated with one of more of the facets. The facet free of pain was nonsignificantly correlated with all facets.

Items showing strongest discriminatory power across groups included sensory abilities, feeling happiness and enjoyment, positive attitudes toward death and dying, community participation, and sex life.

The importance questions showed good internal consistency reliability with $\alpha=.92$.

\section{DISCUSSION}

\section{Important Aspects of QoL}

For nurses interested in enhancing the life quality of older adults in a variety of settings, it is important to establish what aspects of QoL are significant to older adults and whether the same aspects of life are equally important to various subgroups. To the best of our knowledge, the present study is the only study conducted in Norway which systematically assesses important issues in this population.

Findings confirm that importance issues do not decrease with age [31]. All items were found to be moderately to extremely important, a finding supported by international findings $[9,32]$. For the total group, highest mean importance was given to ADL, mobility, sensory abilities, health, and home environment, consistent with findings in the literature $[7-9,11,17]$. Issues ranked somewhat less important were sex life, adequate social help, opportunities to learn new skills, body image and appearance and dependence on medication and treatment, as reported by others [14] although social help has been cited as important in another study [1].

Notably, other standardized instruments typically omit several items which are of importance to the older person's value system $[11,12]$. The only item having a mean score under 3 was sex life. The less importance attributed to this issue has been reported by others [31,33]. Gott and Hinchliff [34], in a sample of adults aged 50 to 92 years of age, used the WHOQOL importance questions followed by semistructured interviews to examine the importance of sex in later life. They reported that all participants who had a current sexual partner attributed at least some importance to sex. However, barriers to sexual activity led them to place less importance on sex, particularly when health problems and widowhood were experienced.

Importance ratings were prioritized differently as influenced by age, gender, marital and health status. Past research indicates that subjective ratings of psychological wellbeing and health are more powerful predictors than socio-demographic indicators in explaining the variance in QoL ratings [35] contrary to our finding which support socio-demographic influences.

\section{Differences in Age Groups}

Our results showed that the younger - aged rated three items significantly more important than older-aged adults. Mental factors such as feeling positive about one's self and having chances to learn new skills were particularly relevant together with sex life. These results differ from youngeraged older British adults who assessed social relations, work, family activities and work as highly important [12]. The importance of having opportunities to learn new things has been cited as being important to older adults in another study [36] although the absence of this issue in QoL assessments has been marked [37]. The importance of a positive self concept has been described as important to emotional wellbeing and adaption to ageing [38, 39]. The importance of this issue to Norwegian older adults was confirmed in a recent survey with participants $40-79$ years of age based upon personal interviews $(n=5,559)$ and postal questionnaires $(n=4$, 169). In this study, self-acceptance was shown to increase up until age 80 [40-42]. The absence of significant associations found among older Norwegians might be explained by the phenomenon of psychological centrality, which involves increasing the importance of domains in which one is doing well and lowering the centrality in which one is not doing so well (i.e. loss of health and relationships) in order to enhance self evaluation. Findings might also reflect that older adults are better able to control exposure or reaction to difficult emotions [33, 43], and are able put one's own life in context, so that one reaches a state of contentment, self-acceptance, sense of purpose and mastery $[40,44]$. 


\section{Differences in Gender and Marital Status}

Comparison of ratings across genders showed that a fourth of the items were more important to women, consistent with others $[9,45]$. Women rated various psychological issues as being important such as feeling hopeful, personal beliefs, positive attitudes towards death and dying, and body image and appearance. Mental activities such as remembering important information, being able to think through everyday activities and make decisions were important alongside the importance given to social relationships. Lubetkin [16] reported lower quality of life among women and suggested that this was related to their low educational status. Contrary, women in our study were highly educated thus the importance given to cognitive and mental factors may have been impacted by their educational status. The reason why women assess a greater number of issues as being important as compared to men is interesting. An explanation may be that women have higher hopes, expectations, and aspirations, thus valuing a greater variety of life aspects. Perhaps the variety of important issues relevant to women, represent their desires, ideals and needs inherent in obtaining self meaning and satisfaction or represent earlier areas of importance in their lives which they are presently trying to maintain. Although women assigned more importance to personal beliefs, a recent review of the literature on QoL among older adults has also documented the importance of spiritual beliefs to older adults QoL in general [1]. Men, on the other hand, rated being free of pain and sex life as being important. In comparing our findings with another study using the importance ratings, women rated 14 items statistically more important, as compared to men, who rated sex life as more important [9]. The importance of social life and personal relationships for women is reported in a number studies [7, 17]. In Bowling's study [12] comparing the most important things in life between younger and older adults, results showed that relationships with family was especially important to younger aged men (65 - 75 years) while relationships with others was important to women over 75 years of age. Further, in both groups of older men, finances and standard of living were given high importance. Both younger and older adults on the other hand, assigned importance to the health of a close relative and religious and spiritual life consistent with our findings. In another preliminary analyses using the importance ratings, ADL was assessed as most important for both women and men and sex life as least important [45]. Contrary our findings, working capacity and opportunities for new knowledge and information did not discriminate according to gender in international pooling [9] although learning new things has been cited as important to older adults in another study [36].

Findings showed that adults who were partnered assigned more importance to feeling happiness and enjoyment in life, environmental conditions (noise, pollution, attractiveness), and sex life. Those not partnered assigned more importance to personal beliefs. In a recent survey, Wahl and colleagues [46] found among Norwegian adults $(n=1983$, range 19-81 years) that those married or cohabitating reported a higher QoL than those living alone. Among newly diagnosed cancer patients, Rustøen and colleagues [47] also found that those Norwegians who were partnered had a higher QoL than those not partnered, consistent with our findings. Also, a recent study [8] found that those partnered tended to report higher QoL. Other studies have also underlined the importance given by older adults to living arrangements [7] and the quality of local residential environments for shaping life opportunities available to older people. Perceived quality of neighbourhood, facilities and safety [15] home environment and emotional well being [8] and quality facilities in the area such as social leisure, rubbish/ litter, health services, transport and closeness to shops have been cited as important. Perception of noise, air quality and traffic have been found to be predictive of not only QoL, but also health among older adults $[12,17]$. The importance given to social environmental factors and the older adult's interaction with their environment should be noted as the fit between individual's and their surroundings is especially relevant in planning future residential strategies for the promotion of well-being later in life [48].

\section{Differences in Hospitalized and Non-hospitalized Groups}

Regarding health status, Skevington et al. [32] examined differences between WHOQOL-100 items and importance ratings in a sample of 4804 people, mean age 38 - 48 years, with women constituting $49-63 \%$ of the sample and those classified as unhealthy representing 70-84\%. Results showed that those with the poorest QoL gave more importance to mobility, having sufficient social support, adequate finances, being free from negative feelings and working capacity. These authors suggested that the importance ratings were highly salient for people with specific health conditions. These results are consistent with our hospitalized/ambulatory patients who also prioritized emotional well being, availability of transport, and receiving adequate social, health-related support. Among the frail elderly, the importance of emotional well being, life satisfaction, and the availability of adequate health and social services, including institutional care has been documented by others [15]. Those not hospitalized assigned importance to sensory functioning, work, positive attitudes, personal beliefs and community participation. These finding are congruous with another study among the healthy aged where freedom from depression, personal optimism, well retained cognitive abilities, transport and aspects of the social environment found were given highest priority [8]. These findings support the claim that health, health related services and aspects of the environment among unhealthy groups take on increasing importance $[11,15,33,36]$ also suggesting that the measurement of QoL among older adults requires a wide social perspective, reflecting opportunities available in society. Moreover, for both groups the importance of positive feelings was found. Although health has been shown to be a main predictor of both life satisfaction and happiness among older adults $[49,50]$, optimism has being described as specifically central to older adults mental health [51]. Such beliefs are described as vital reserves in enabling people to cope effectively underlying the importance of personality characteristics to QoL [52].

\section{Importance Items and Core Items}

Almost one half of the items were found to detect significant between-group differences, establishing support for the discriminatory power of the items. It was interesting to note that the importance of overall QoL and health did not detect group differences. Others have suggested the limited use of global questions as being vague and nonspecific (ambiguous and 
unreliable) in documenting importance on their own [2]. Further, low correlations were found between the important ratings and the WHOQOL-100 items. Others have found that the core items and importance questions showed few correlations with each other, congruous with our results [32]. This is somewhat surprising as both core and importance ratings are derived from a common QoL stem. However, there is evidence that for most instruments, QoL domains are selected on the basis of their inherent importance, possibly rendering separate importance ratings partially redundant. The low correlations found in our study and international findings do not support this idea of redundancy. It could be claimed that both assessments may be tapping different aspects of QoL and/or differing acquisition processes in older adults. For example, it is suggested there are several distinct cognitive activities associated with generating a QoL assessment. These processes includes recall from memory, sealing of memories, valuing the importance of memories and aggregating the importance of memories into an index [53]. Consequently, differences in cognitive tasks such as ordering and recruiting information from memory in the different assessments may tap differing cognitive processes and explain the low correlations.

Another explanation could be that global questions are more likely to be influenced by the emotional characteristics of the person [53], although older adults are reported to have a remarkable constancy or stability in their basic trait personality characteristics [54]. Further, both assessments operate with different time frames. The importance ratings have no time frame and the WHO core questions have a two-week frame. The period of accurate recall for feeling states is between 2 and 4 weeks [28], and consequently, low correlations could reflect varying trait or state tendencies.

Differences in question formatting and combining different response scales in the WHO core instrument could also lead to differences in cognitive processing and the information generated by the assessments. Each response scale includes descriptors for dimensions of intensity, capacity, frequency and evaluation of each response as reflected by the wording in the response categories. These responses range from (5) representing descriptors including; very good, very satisfied, an extreme amount, extremely, completely, and always to (1) representing very poor, very dissatisfied, not at all, very poor, and never. For the importance questions, each question included different response categories ranging from (1) not important, (2) a little, (3) moderately, (4) very and (5) extremely important.

\section{Future Implications}

The differing priorities as shown by the subgroups in this study, present challenges to critical scale development [55]. A major issue in QoL measurement is deciding whether various items should be weighted and what weight should be given to specific dimensions of the concept. If weight is not given to any of the dimensions, than one is in fact using weighting by selection or rejection. The WHO instruments are said to be conceptually novel in that they give equal weight to the person's level of functioning [56]. However, Fayers and Machin [2] proclaim that if measurement scales give equal weight to QoL sub domains, it is inconceivable that each issue is equally important in its effect upon a person's QoL. Our findings showed that although older adults found all the important questions relevant, significant between-group variations existed.

Although, the importance ratings were not originally intended to serve as a scale per se, the internal consistency of the scale showed high reliability at .92 . In the international study, Guttman coefficients for 14 centers showed high reliability from .80 to .90 [9]. These findings together with low item-to-item and item-to-facet correlations, may suggest potential use of the ratings as a reliable index. Because the importance ratings are not presently used for weighting WHOQOL core items, one can also question wheather the WHOQOL assessments should be scaled differently in various groups or whether weights should be self-normed by individuals to account for changes in priorities over time [5].

\section{Methodological Considerations}

There are certain limitations to the study. Using convenience samples has also been shown to contribute to sampling bias and weaken the generalizability of the findings [57]. Differences in recruitment strategies as well as differing modes of questionnaire administration pose threats to the validity of our findings. Considerable uncertainly exists about the optimal method for questionnaire administration among older adults [58, 59]. Direct interviewing techniques are usually recommended, although postal surveys are advised for reducing cost effects and increasing the validity of the findings $[60,61]$. A postal survey was applied in the non hospitalized group because we wanted to secure a wide geographical dispersal and anonymity of the participants. The disadvantages of this mode of administration include the potential for lower response rates, respondent bias (by excluding older adults with linguistic, literacy or visual problems) higher completion rates by women and poor levels of completion. Our response rate of $43 \%$ is similar to the response rate found in other Norwegian postal surveys [62-64] although international studies have shown higher response rates $[65,66]$. It has been suggested that lower response rates may not give more biased estimates than those with higher response rates [67]. Notably, the postal data had $20.3 \%$ missing answers. It can be considered a strength, however, that most geographical areas in Norway were represented in the postal survey although women were overrepresented under both modes of administration, a finding supported by others [68]. Because elderly patients are often admitted to the hospital in an advanced state of their disease [66], face-to-face interviews have been especially recommended among frailer adults due to decreased functional capacity [69]. Selection bias could have occurred as contact nurses identified study participants with adequate cognitive functioning. Moreover, interviewing style, personality style, observer competency and sensitivity all represent sources of potential bias with personal interviews. Studies have also shown that older adults give more positive and socially desirable responses and apply more "yes-saying" in face-to-face interview surveys as compared to self-administered surveys $[63,69,70]$. In an earlier Norwegian survey, more socially desirable responding was found in face-to face interviews as compared to the self administrative mode (5) and the well - educated with both modes of administration were shown to under-report negative symptoms. Because two - thirds of our respondents had higher education, this poses a validity threat to the quality of data collected. The fact that that respondents are willing to answer more sensitive issues in postal surveys is confirmed by our findings [66]. The most frequent missing response concerned 
sex life in the postal survey $(8.7 \%)$ as compared to $10.7 \%$ with personal interviewing. All these issues should be regarded as sources of bias thus results should be interpreted with caution.

\section{CONCLUSION}

All importance issues were found to be moderate to highly important for older adults with the exception of sex life. Highest mean importance was given to the ability to perform ADL activities, ability to move around, sensory abilities, health, and home environment. There are significant differences in the importance given to various aspects of QoL by younger old and older old and for women and men. Similarly, there are differences in areas of importance for those partnered and not and for persons hospitalized and not hospitalized.

Understanding what is important to older adults' QoL can help nurses in setting priorities in policy and treatment strategies for ageing populations. Future application of the importance questions could facilitate understanding and recognition of importance issues in subgroups of older adults. Further research is needed to assess how the importance ratings vary in other elderly populations and cultures.

\section{ACKNOWLEDGEMENTS}

The authors would like to acknowledge the contributions of the WHOQOL-OLD Group in the design of the original study. We are most appreciative to the older adults who were willing to participate in the pilot study. Funding for the original project was obtained from the European Commission $5^{\text {th }}$ Framework Competition and Diakonova University College, Oslo. We are also grateful to our anonymous referees.

\section{CONTRIBUTION OF AUTHORS}

MK and LH contributed to the study design and analyzed the data, LH collected the data, and MK drafted manuscript versions.

\section{REFERENCES}

[1] Brown J, Bowling A, Flyn T. Models of QoL: a taxonomy, overview and systematic review of the literature. Report Commissioned by European Forum on Population Ageing Research, Bristol 2004.

[2] Fayers PM, Machin D. Quality of life: the assessment, analysis and interpretation of patient-reported outcomes. Chichester: John Wiley 2007.

[3] Felce D. Defining and applying the concept of quality of life. J Intellect Disabil Res 1997; 41: 126-35.

[4] Cummins RA. Assessing quality of life for people with disabilities. In: Brown R, Ed. Quality of life for people with disabilities: models, research and practice. Cheltenham, UK, Stanley Thornes. 1997; pp. 116-50.

[5] Carr AJ, Higginson IJ. Are quality of life measures patient centred? BMJ 2001; 322: 1357-60.

[6] The WHOQOL Group. Study protocol for the World Health Organization project to develop a Quality of Life assessment instrument (WHOQOL). Qual Life Res 1993; 2: 153-9.

[7] Evans S, Gately C, Huxley P, Smith A, Banerjee S. Assessment of quality of life in later life: development and validation of the QuiLL. Qual Life Res 2005; 14: 1291-300.

[8] Beaumont JG, Kenealy PM. Quality of life perceptions and social comparisons in healthy old age. Ageing Soc 2004; 24: 755-69.

[9] Saxena S, Carlson D, Billington R, WHOQOL Group. World Health Organisation Quality Of Life. The WHO quality of life assessment instrument (WHOQOL-Bref): the importance of its items for cross-cultural research. Qual Life Res 2001; 10: 711-21.
[10] Bowling A. The effects of illness on quality of life: findings from a survey of households in Great Britain. J Epidemiol Commun Health 1996; 50: 149-55.

[11] Bowling A. What things are important in people's lives? A survey of the public's judgements to inform scales of health related quality of life. Soc Sci Med 1995; 41: 1447-62.

[12] Bowling A. The most important thing in life: comparison between older and younger populations age groups by gender. Results from a national survey of the public`s judgement. Int J Health Sci 1995; 6: 169-75.

[13] Farquhar M. Elderly people's definitions of quality of life. Soc Sci Med 1995; 41: 1439-46.

[14] Puts MT, Shekary N, Widdershoven G, Heldens J, Lips P, Deeg DJ. What does quality of life mean to older frail and non-frail community-dwelling adults in the Netherlands? Qual Life Res 2007; 16: 263-77.

[15] Arnold SB. Measurement of quality of life in the frail elderly. In: Birren JE, Lubben JE, Rowe JC, Deutchman DE, Eds. The concept and measurement of quality of life in the frail elderly. San Diego: Academic Press 1991; pp. 50-73.

[16] Lubetkin EI, Jia H, Franks P, Gold MR. Relationship among sociodemographic factors, clinical conditions, and health-related quality of life: examining the EQ-5D in the U.S. general population. Qual Life Res 2005; 14: 2187-96.

[17] Bowling A, Gabriel Z. An integrational model of quality of life in older age: results from the ESRC/MRC HSRC quality of life survey in Britain. Soc Indic Res 2004; 69: 1-36.

[18] Ng CY, Ballantyne JA, Brenkel IJ. Quality of life and functional outcome after primary total hip replacement: a five-year follow-up. J Bone Joint Surg Am 2007; 89: 868-73.

[19] al Windi A, Elmfeldt D, Tibblin G, Svardsudd K. The influence of sociodemographic characteristics on well-being and symptoms in a Swedish community: results from a postal questionnaire survey. Scand J Prim Health Care 1999; 17: 201-9.

[20] Hellstrom Y, Hallberg IR. Determinants and characteristics of help provision for elderly people living at home and in relation to quality of life. Scand J Caring Sci 2004; 18: 387-95.

[21] Power M, Quinn K, Schmidt S. Development of the WHOQOLOld module. Qual Life Res 2005; 14: 2197-214.

[22] The WHOQOL Group. The world health organization quality of life assessment (WHOQOL): development and general psychometric properties. Soc Sci Med 1998; 46: 1569-85.

[23] The WHOQOL Group. The world health organization quality of life assessment (WHOQOL): position paper from the world health organization. Soc Sci Med 1995; 41: 1403-9.

[24] Szabo S, Orley J, Saxena S. An approach to response scale development for cross-cultural questionnaire. Eur Psychol 1997; 2 270-6.

[25] SPSS. Version 14.0.2. Chicago, IL: SPSS Inc; 2006

[26] Campbell MJ, Machin D. Medical Statistics: a commonsense approach. Chichester: Wiley 1999.

[27] Garratt A, Schmidt L, Mackintosh A, Fitzpatrick R. Quality of life measurement: bibliographic study of patient assessed health outcome measures. Br Med J 2002; 324: 1417.

[28] Nunnally J, Bernstein IH. Psychometric Theory. $3^{\text {rd }}$ ed. New York: McGraw-Hill 1994.

[29] Streiner DL, Norman GR. Health measurement scales: a practical guide to their development and use. $3^{\text {rd }}$ ed. Oxford: Oxford University Press 2003.

[30] The WHOQOL-OLD Group, The WHOQOL-OLD manual. World health organization (WHO) group, Copenhagen (WHO/EURO). 2005.

[31] Campbell A, Converse PE, Rodgers WJ. The quality of American life: perceptions, evaluations, and satisfactions. New York: Russell Sage 1976.

[32] Skevington SM, O'Connell KA, WHOQOL Group. Can we identify the poorest quality of life? Assessing the importance of quality of life using the WHOQOL-100. Qual Life Res 2004; 13: 23-34.

[33] Frytak JR. Assessment of quality of life in older adults. In: Kane RL, Kane RA, Eells M, Eds. Assessing older persons: measures, meaning, and practical applications. Oxford: Oxford University Press 2000; pp. 200-36.

[34] Gott M, Hinchliff S. How important is sex in later life? The views of older people. Soc Sci Med 2003; 56: 1617-28. 
[35] Bowling A, Banister D, Sutton S, Evans O, Windsor J. A multidimensional model of the quality of life in older age. Aging Ment Health 2002; 6: 355-71.

[36] Fernàndez-Ballesteros R. The construct of quality of life among the elderly. In: Beregi E, Gergely AA, Rajczi K, Eds. Recent advances in ageing science. Bologna: Italy-Monduzzi Editore spA 1993.

[37] Schalock RL, Alonso MVV. Handbook on quality of life for human service practitioners. Washington, DC: American Association on Mental Retardation 2002.

[38] Heidrich SM, Ryff CD. Physical and mental health in later life: the self-system as mediator. Psychol Aging 1993; 8: 327-38.

[39] Kling KC, Ryff CD, Essex MJ. Adaptive changes in the selfconcept during a life transition. Pers Soc Psychol Bull 1997; 23: 981-90.

[40] Daatland SO, Hansen T. Well-being, control and ageing. An empirical assessment. In: Mollenkopf H, Walker A, Eds. Quality of life in old age: international and multi-disciplinary perspectives. Heidelberg: Springer 2007; pp. 33-47.

[41] Daatland SO. Age identification. In: Fernández-Ballesteros R, Ed. Geropsychology. European Perspectives for an Ageing World. Cambridge, MA: Hogrefe \& Huber Publishers 2007; pp. 31-48.

[42] Hansen T, Slagsvold B, Moum T. Financial satisfaction in old age: a satisfaction paradox or a result of accumulated wealth? Soc Ind Res 2008; DOI: 10.1007/s11205-007-9234-z. [Retrieved: Dec 2008].

[43] Ryff C. Psychology and ageing. In: Hazzard WR, Andres R, Eds. Principles of geriatric medicine and gerontology. New York: McGraw-Hill 1994.

[44] Blazer DG. Self-efficacy and depression in late life: a primary prevention proposal. Aging Ment Health 2002; 4: 315-24.

[45] Power M, Ed. Pilot data analyses. Oslo, Norway, Paper presented at a meeting of the WHOQOL Assessment Workgroup Meeting 2003.

[46] Wahl AK, Rustoen T, Hanestad BR, Lerdal A, Moum T. Quality of life in the general Norwegian population, measured by the Quality of Life Scale (QOLS-N). Qual Life Res 2004; 13: 1001-9.

[47] Rustoen T, Moum T, Wiklund I, Hanestad BR. Quality of life in newly diagnosed cancer patients. J Adv Nurs 1999; 29: 490-8.

[48] Wahl HW. Environmental influences on aging and behaviour. In: Birren James E, Schaie KW, Abeles RP, Eds. Handbook of the Psychology of Ageing. San Diego: Academic Press 2001; pp. 21537.

[49] Michalos AC, Zumbo BD, Hubley A. Health and quality of life. Soc Ind Res 2000; 50: 245-95.

[50] Bowling A, Farquhar M, Grundy EE. Associations with changes in life satisfaction among three samples of elderly people living at home. Int J Geriatr Psychiatry 1996; 11: 1077-87.

[51] Gatz M, Zarit S. A good old age: paradox or possibility? In: Bengtson VL, Schaie KW, Eds. Handbook of theories of aging. New York, Springer Pub. Co. 1999; pp. 396-416.

[52] Taylor SE, Kemeny ME, Reed GM, Bower JE, Gruenewald TL. Psychological resources, positive illusions, and health. Am Psychol 2000; 55: 99-109.

[53] Barnofsky I. I. Cognitive aspects of quality of life assessment. In: Spilker B, Ed. Quality of life and pharmacoeconomics in clinical trials. Philadelphia: Lippincott-Raven 1996.
[54] McCrae RR, Costa PT. Emerging lives, enduring dispositions: personality in adulthood. Boston: Little Brown 1984.

[55] Juniper EF, Guyatt G, Jaeschke F. How to develop and validate a new health related quality of life instrument. In: Spilker B, Ed. Quality of life and pharmacoeconomics in clinical trials. Philadelphia: Lippincott-Raven 1996.

[56] Skevington SM, Sartorius N, Amir M. Developing methods for assessing quality of life in different cultural settings. The history of the WHOQOL instruments. Soc Psychiatr Epidemiol 2004; 39: 1-8

[57] Coolican H. Research methods and statistics in psychology. $4^{\text {th }} \mathrm{Ed}$. London: Hodder \& Stoughton 2004.

[58] Smeeth L, Fletcher AE, Stirling S, et al. Randomised comparison of three methods of administering a screening questionnaire to elderly people: findings from the MRC trial of the assessment and management of older people in the community. BMJ 2001; 323: 1403-7.

[59] Hebert R, Bravo G, Korner-Bitensky N, Voyer L. Refusal and information bias associated with postal questionnaires and face-toface interviews in very elderly subjects. J Clin Epidemiol 1996; 49: 373-81.

[60] McHorney CA. Measuring and monitoring general health status in elderly persons: practical and methodological issues in using the SF-36 Health Survey. Gerontologist 1996; 36: 571-83.

[61] Victor CR. Some methodological aspects of using postal questionnaires with the elderly. Arch Gerontol Geriatr 1988; 7 163-72.

[62] Ihlebæk C, Eriksen HB, Urisin H. Prevalence of subjective health complaints (SHC) in Norway. Scand J Public Health 2002; 30: 20 9.

[63] Moum T. Mode of administration and interviewer effects in selfreported symptoms of anxiety and depression. Soc Indic Res 1998; 45: 279-318.

[64] Rustoen T, Wahl AK, Hanestad BR, Lerdal A, Paul S, Miaskowski C. Prevalence and characteristics of chronic pain in the general Norwegian population. Eur J Pain 2004; 8: 555-65.

[65] Addington-Hall J, Walker L, Jones C, Karlsen S, McCarthy M. A randomised controlled trial of postal versus interviewer administration of a questionnaire measuring satisfaction with, and use of, services received in the year before death. J Epidemiol Commun Health 1998; 52: 802-7.

[66] Doll H, McPherson K, Davies J, et al. Reliability of questionnaire responses as compared with interview in the elderly: views of the outcome of transurethral resection of the prostate. Soc Sci Med 1991; 33: 1303-8.

[67] Lund E, Gram IT. Response rate according to title and length of questionnaire. Scand J Soc Med 1998; 26: 154-60.

[68] Picavet HS. National health surveys by mail or home interview: effects on response. J Epidemiol Commun Health 2001; 55: 40813

[69] Bowling A. Mode of questionnaire administration can have serious effects on data quality. J Public Health 2005; 27: 281-91.

[70] Tourangeau R, Smith TW. Asking sensitive questions: the impact of data collection mode, question format, and question context. Opin Q 1996; 60: 275-304. 